\title{
DOSSIÊ INCLUSÃO E DIVERSIDADE, EXCLUSÃO, FORMAÇÃO DE PROFESSORES
}

\section{DOSSIÉ INCLUSIÓN Y DIVERSIDAD, EXCLUSIÓN, FORMACIÓN DE PROFESORES}

DOSSIÊ INCLUSION AND DIVERSITY, EXCLUSION, TEACHER TRAINING

\author{
Osmar Hélio Alves ARAÚJO ${ }^{1}$ \\ Janine Marta Coelho RODRIGUES ${ }^{2}$ \\ Wilson Honorato ARAGÃO ${ }^{3}$
}

(Orgs.)

O objetivo desta Edição Especial é o de contribuir para a reflexão nesses campos permeados por controvérsias, desafios e perspectivas. Pois, em tempos de discurso sobre a Inclusão e Exclusão, Diversidade, Formação dos professores, entre outras temáticas, faz-se necessárias análises crítico-reflexivas que fomentem uma Política Nacional de Educação em uma perspectiva inclusiva, assim como novos olhares e reflexões sobre a formação e a valorização profissional do professor pela importância que assumem na formação e no sucesso dos resultados da aprendizagem dos discentes.

Em geral, como explica Candau (2016), e nós concordamos, o termo diferença, a partir dos depoimentos dos professores, é cotidianamente associado a um problema a ser resolvido, à deficiência, ao déficit cultural e à desigualdade. Percebemos, ainda, o termo diferente ser utilizado em relação aos alunos que apresentam baixo rendimento; aos alunos oriundos de comunidades de risco, de famílias em condições de vulnerabilidade, assim como em relação aos alunos que apresentam comportamentos com níveis diversos de violência e incivilidade, ou possuem características identitárias que são associadas à 'anormalidade', ou a um considerado baixo 'capital cultural'. Enfim, a autora resume que os diferentes representam um problema que a escola e os professores dizem, muitas vezes, enfrentar. Bem como que, somente em poucos depoimentos percebe-se a diferença articulada a identidades plurais que enriquecem os processos pedagógicos e

${ }^{1}$ Universidade Regional do Cariri (URCA), Campus Missão Velha - CE - Brasil. Docente do Departamento de Línguas e Literaturas. E-mail: osmarhelio@ hotmail.com.

${ }^{2}$ Universidade Federal da Paraíba (UFPB), João Pessoa - PB -Brasil. Programa de Pós-Graduação em Educação -Mestrado e Doutorado. Professora titular. E-mail: jmcoelho@ig.com.br.

${ }^{3}$ Universidade Federal da Paraíba (UFPB), João Pessoa - PB - Brasil. Diretor do Centro de Educação/UFPB (2013-2016). Professor Associado II do Programa de Pós-Graduação em Educação. Email: wilsonaragao@hotmail.com. 
devem ser reconhecidas e valorizadas. Entretanto, é por esse viés que entendemos e trabalhamos aqui a inclusão e a diversidade. Ou seja, a heterogeneidade presente na sala de aula precisa ser reconhecida e valorizada.

Assim, os artigos da primeira seção desta edição, com foco notadamente na inclusão e diversidade, assim como na exclusão, acabam por refletir sobre a necessidade de atividades plurais promovidas no contexto escolar; as diferenças como vantagem pedagógica; a inclusão como um processo de transformação e reconstrução das escolas; o papel preponderante dos professores no processo educativo de todos os alunos, entre outros pontos discutidos e problematizados, quais sejam:

- $\quad$ Práticas pedagógicas de acolhimento e inclusão: a perspectiva da pedagogia critica, de autoria da Maria Amélia Santoro Franco.

- $\quad$ O que os gestores escolares da rede pública entendem sobre gênero? De autoria de Lia Machado Fiuza Fialho e Lorena Brenda Santos Nascimento.

- Entre a exigência de qualidade no trabalho pedagógico e a inclusão de alunos com deficiência no Ensino Médio e na universidade, de autoria de Manoel Pinéo de Sousa; Maria Socorro Lucena Lima e Regiane Rodrigues Araújo.

- Políticas públicas de educação no Brasil: fracasso escolar, culpabilização dos alunos e inocentização da escola, de autoria de Janine Marta Coelho Rodrigues, Wilson Honorato Aragão e Silvestre Coelho Rodrigues.

- SAGA Cigana: narrativas (auto) biográficas intergeracionais na comunidade do bairro Sumaré no município de Sobral-CE, de autoria de Liana Lopes Liberato Carlos e Andrea Abreu Astigarraga.

- $\quad$ Práticas inclusivas de alunos com TEA: principais dificuldades na voz do professor e mediador, de autoria de Célia de Jesus Silva Magalhães, Cloves Santos de Moraes, Jaíze Griffith Magalhães Cruz e Lígia Maria Tavares Sampaio.

- Inter-relação entre professores da sala de atendimento educacional especializado e do ensino regular, de autoria Betania Jacob Stange Lopes, Hellen Karolinni Rocha Souza, Kelly Vital e Valéria de Oliveira Duarte.

- $\quad$ Superdotação/altas habilidades percebidas por pais e professores do ensino fundamental, nível I, de autoria Betania Jacob Stange Lopes, Alexandra Imaculada de Oliveira e Medeiros, Letycia Pedroso Alencar e Nathalya Elizabeth Ferrer Ubeda. 
- Educação em e para os direitos humanos: a escola e o direito a afirmação da diferença, de autoria de Tarcia Regina da Silva.

- $\quad$ O papel da afetividade na relação professor e aluno e suas implicações na aprendizagem, de autoria de Fabrícia Medeiros.

- $\quad$ Exclusão/exclusão: múltiplos olhares, diferentes significados, de autoria de Sandra Cristina Souza.

- $\quad$ Avaliação da aprendizagem e inclusão escolar: um processo de exclusão ou um ato de amor, de autoria de Maria das Graças de Almeida Baptista, Tânia Rodrigues Palhanoe Aline dos Santos Pereira.

Reiteramos que o objetivo dessa primeira seção é o de contribuir para as discussões sobre a necessidade de se reconhecer e valorizar a dignidade de todos os alunos, as diferenças, as especificidades e capacidades de desenvolvimento de cada discente, pois "há diferenças e há igualdades, e nem tudo deve ser igual nem tudo deve ser diferente, [...] é preciso que tenhamos o direito de ser diferente quando a igualdade nos descaracteriza e o direito de ser iguais quando a diferença nos inferioriza" (MANTOAN, 2003, p. 7-8). Logo, "As escolas precisam passar por profundas transformações em suas práticas e culturas para enfrentarem os desafios do mundo contemporâneo" (SEVERINO; PIMENTA, 2002, p. 12) e construírem, de fato, uma educação pública com qualidade e inclusiva.

Em seguida, a formação dos professores em suas nuances será o foco das discussões da segunda seção, pois a formação docente, seja inicial ou contínua, deve permitir e levar os professores a viver "[...], na profissão, uma experiência prazerosa, valorizada por permitir desvendar novas formas de ser, pensar e sentir, e por levar à construção de projetos coletivos para o mundo em que se vive" (DAVIS et al, 2011, p. 830). Neste sentido, temos:

- O grupo de estudo-reflexão perspectiva teórico-metodológica para formação continuada: um estudo com gestores públicos de educação especial, de autoria de Mariangela Lima de Almeida, Rayner Raulino e Silva e Janaina Borges Alves.

- Formação continuada de professores: racionalidade técnica versus desenvolvimento profissional, de autoria de Rayane R. S. Gasparelo.

- $\quad$ O diálogo intercultural e a formação de professores na ANPED (20022015): há a inclusão ou exclusão? De autoria de Sawana Araújo Lopes de Souza. 
- $\quad$ Relato de experiência no Estágio Supervisionado I no Ensino Infantil, de autoria de Francisco Claudeci Faustino Teixeira, Ana Paula Mendes Santiago Jacqueline de Oliveira Lima, Stela Lopes Soares e Heraldo Simões Ferreira.

- $\quad$ Entre pontos e nós: a produção científica sobre educação especial no Curso de Pedagogia da UVA-Sobral-CE, de autoria de Wildiane Gonçalves do Nascimento, Railane Bento Vieira, Rejane Maria Gomes da Silva, Ana Cristina Sousa Soares e Francisco Ricardo Miranda Pinto.

- Política de avaliação em larga escala: "Educação para todos" ou exclusão em nome da "qualidade”? De autoria de Silmara Cássia.

- $\quad$ O papel do educador na sociedade pós-moderna, de autoria de Aureliana Tavares e Ana Maria Barreiro.

- $\quad$ Formação de professores alfabetizadores: a perspectiva de alfabetizar letrando: avanços e desafios, de autoria de Vera Maria Souto Alves.

- $\quad$ Reconhecimento do notório saber e a inclusão excludente do professor na educação básica: qual o lugar da universidade na formação? De autoria de Jussara Marques de Macedo.

- Educação em direitos humanos e desenvolvimento moral na formação docente: a influência da religiosidade em tempos de "ideologia de gênero", de autoria de Matheus Estevão.

- Escolas Bilingues para surdos no Brasil: uma luta a ser conquistada, de autoria de Edileuza Lima Freire, Neudiane Moreira Feli e Anaisa Alves de Moura.

- Gestão escolar e a política nacional de educação especial: as barreiras para a implementação de uma política pública, de autoria de Daniel Marcelino dos Santos e Ivone Panhoca.

- $\quad$ Avaliação da aprendizagem do aluno com deficiência na perspectiva da inclusão escolar, de autoria de Romária de Menezes do Nascimento, Ana Cristina Silva Soares, Rejane Maria Gomes da Silva e Francisco Ricardo Miranda Pinto.

Cabe, por fim, ressaltar que inclusão e diversidade, assim como exclusão, são desafios que precisam ser assumidos, teórica e praticamente, e principalmente discutidos/problematizados na formação inicial e contínua dos professores, pois, como advertem Pimenta e Anastasiou (2002), as escolas estão fragilizadas e não conseguem ensinar tudo a todos; os professores se defrontam com a questão do que e como ensinar, 
e toda a sociedade, sem dúvida, não tem resposta para a questão: para que ensinar?, entre outras perguntas ainda em aberto.

\section{REFERÊNCIAS}

PIMENTA, Selma Garrido.; ANASTASIOU, Léa das Graças Camargos. Docência no ensino superior. São Paulo: Cortez, 2002.

CANDAU, Vera Maria. Ensinar - Aprender: desafios atuais da profissão docente.

Revista COCAR, Belém, Edição Especial n.2, p. 298-318, ago./dez. 2016. Disponível em: <https://paginas.uepa.br/seer/index.php/cocar/article/view/1035>. Acesso em: 02 maio 2016.

DAVIS, Claudia Leme Ferreira et al. Formação continuada de professores em alguns estados e municípios do Brasil. Cadernos de pesquisa, v.41 n.144 set./dez. 2011. Disponível em: <http://publicacoes.fcc.org.br/ojs/index.php/cp/article/view/77/89 >. Acesso em: 10 out. 2017.

MANTOAN, M. T. E. Inclusão escolar: o que é? por quê? como fazer? São Paulo: Moderna, 2006.

AGRADECIMENTOS: Thaís Conte Vargas, pela revisão desta apresentação redação, gramática e ortografia; Mariana Bulegon da Silva, pela revisão e tradução desta apresentação em Espanhol; Raquel Juliane Ribeiro de Faria, pela revisão dos artigos que compõe este dossiê; Ao Prof. Dr. Sebastião de Souza Lemes pela colaboração, confiança e avaliação deste dossiê; Ao Prof. Me. José Anderson Santos Cruz pelo trabalho de organização e editoração; e a todos os autores que nos prestigiaram com seus textos, dessa forma, enaltecendo a pesquisa em educação.

\section{Cómo citar este texto:}

ARAÚJO, Osmar Hélio Alves.; RODRIGUES, Janine Marta Coelho.; ARAGÃO, Wilson Honorato. Apresentação Dossiê: Inclusão e diversidade, exclusão, formação de professores. Revista on line de Política e Gestão Educacional, Araraquara, v.21, n. esp.2, p. 915-919, nov./2017. Disponível em: <http://dx.doi.org/10.22633/rpge.v21.n.esp2.nov.2017.apt>. ISSN: 1519-9029.

Submissão em: 04/03/2017

Aceito em: 04/05/2017

Aprovação final: 30/09/2017 